\title{
Investigations into the emergence of pertactin-deficient Bordetella pertussis isolates in six European countries, 1996 to 2012
}

A Zeddeman ${ }^{1}$, M van Gent ${ }^{1}$, C J Heuvelman ${ }^{1}$, H G van der Heide ${ }^{1}$, M J Bart ${ }^{1}$, A Advani ${ }^{2}$, H 0 Hallander ${ }^{2}$, C H Wirsing von Königis,

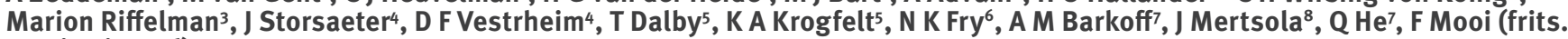
mooi@rivm.nl) ${ }^{1}$

1. Centre for Infectious Diseases Research, Diagnostics and Screening (IDS), Centre for Infectious Diseases Control (CIb),

National Institute of Public Health and the Environment (RIVM), the Netherlands

2. Swedish Institute for Communicable Disease Control, Solna, Sweden

3. Institut für Hygiene und Labormedizin, Krefeld, Germany

4. Norwegian Institute of Public Health, Oslo, Norway

5. Statens Serum Institut, Copenhagen, Denmark

6. Public Health England, London, United Kingdom

7. National Institute for Health and Welfare, Turku, Finland

8. Turku University Hospital, Department of Pediatrics, Turku, Finland

Citation style for this article:

Zeddeman A, van Gent M, Heuvelman CJ, van der Heide HG, Bart MJ, Advani A, Hallander HO, Wirsing von König CH, Riffelman M, Storsaeter J, Vestrheim DF, Dalby T, Krogfelt KA, Fry NK, Barkoff AM, Mertsola J, He Q, Mooi F. Investigations into the emergence of pertactin-deficient Bordetella pertussis isolates in six European countries, 1996 to 2012. Euro Surveill. 2014;19(33):pii=20881. Available online: http://www.eurosurveillance.org/ViewArticle.aspx?Articleld=20881

Article submitted on 12 November 2013 / published on 21 August 2014

Pathogen adaptation has been proposed to contribute to the resurgence of pertussis. A striking recent example is the emergence of isolates deficient in the vaccine component pertactin (Prn). This study explores the emergence of such Prn-deficient isolates in six European countries. During 2007 to 2009, 0/83 isolates from the Netherlands, $0 / 18$ from the United Kingdom, 0/17 Finland, 0/23 Denmark, 4/99 Sweden and 5/20 from Norway of the isolates collected were Prn-deficient. In the Netherlands and Sweden, respectively 4/146 and $1 / 8$ were observed in a later period (2010-12). The Prn-deficient isolates were genetically diverse and different mutations were found to inactivate the prn gene. These are indications that Prn-deficiency is subject to positive selective pressure. We hypothesise that the switch from whole cell to acellular pertussis vaccines has affected the balance between 'costs and benefits' of Prn production by Bordetella pertussis to the extent that isolates that do not produce Prn are able to expand. The absence of Prn-deficient isolates in some countries may point to ways to prevent or delay the spread of Prn-deficient strains. In order to substantiate this hypothesis, trends in the European B. pertussis population should be monitored continuously.

\section{Introduction}

Introduction of whole cell pertussis vaccines (WCVs) 50 to 60 years ago has greatly reduced the pertussis burden worldwide [1]. However, despite a vaccine coverage between $80 \%$ and $96 \%$, pertussis has resurged in many countries $[2,3]$. In particular, in the last few years, high incidences have been observed in the Netherlands, the United Kingdom (UK) and the United States (US) [4-6]. Several causes have been proposed for the resurgence of pertussis, including waning immunity and pathogen adaptation [7].
In the 1990s, less-reactive acellular pertussis vaccines (ACVs) replaced WCVs. ACVs contain between one and five pertussis proteins: (i) pertussis toxin (Ptx); (ii) pertactin (Prn); (iii) serotype 2 fimbriae (Fim2); (iv) serotype 3 fimbriae (Fim3); and (v) filamentous haemagglutinin (FHA). All ACVs contain Ptx. The effectiveness of the different available WCVs was highly variable [8], which complicates evaluation of the protection that ACVs induce compared with that of WCVs. However, recently, several studies have indicated that the immunity induced by ACVs is less long-lasting compared with effective WCVs, resulting in a higher pertussis burden, particularly in children aged 6 to 10 years [9-12].

The effect of waning immunity may have been aggravated by pathogen adaptation [7], which is reflected in large shifts in Bordetella pertussis populations [13-15]. Observed adaptations include antigenic divergence between circulating strains and vaccine strains, and the emergence of strains with a novel promoter for Ptx ( $\left.p x_{x} P_{3}\right)$ [16]. In addition, most recently, strains have emerged that do not express Prn, hereafter named Prn-deficient strains [17-22]. Isolates with the $p t_{x} P_{3}$ promoter increased in frequency in the 1980 s and at present they predominate in many countries, reflecting a global selective sweep $[6,13,16,23-26]$. The $p t x P_{3}$ isolates produce higher amounts of Ptx in vitro (1.6fold increase), when compared with the $p t x P_{1}$ isolates they replaced [16]. It has been suggested that this may result in a more effective suppression of host immunity [16]. In agreement with this, $p t_{x} P_{3}$ isolates reach higher bacterial densities than $p t x P_{1}$ isolates in mice [27]. Prndeficient isolates emerged around 2000 and have been found in Finland, France, Japan and the US [18-20,22]. In addition, less frequently, isolates were found that 


\begin{tabular}{|c|c|c|c|c|c|c|c|c|}
\hline \multirow{2}{*}{ Country } & \multirow{2}{*}{$\begin{array}{l}\text { Year of ACV } \\
\text { introduction }\end{array}$} & \multicolumn{2}{|c|}{$\begin{array}{l}\text { Primary series } \\
\text { Age } \ll 13 \text { months }\end{array}$} & \multicolumn{2}{|c|}{$\begin{array}{c}\text { Childhood booster } \\
\text { Age } 13 \text { months-10 years }\end{array}$} & \multicolumn{2}{|c|}{$\begin{array}{l}\text { Adolescent booster } \\
\text { Age 11-20 years }\end{array}$} & \multirow[t]{2}{*}{ Reference } \\
\hline & & $\mathrm{ACV}^{\mathrm{c}}$ & $\begin{array}{l}\text { Vaccination } \\
\text { coverage }\end{array}$ & $\mathrm{ACV}^{\mathrm{c}}$ & $\begin{array}{l}\text { Vaccination } \\
\text { coverage }\end{array}$ & $\mathrm{ACV}^{\mathrm{c}}$ & $\begin{array}{l}\text { Vaccination } \\
\text { coverage }\end{array}$ & \\
\hline \multirow{2}{*}{ Denmark } & 1997 & 1 & $>90 \%$ & - & - & - & - & \multirow{2}{*}{ [39] } \\
\hline & 2003 & - & - & 1 & $180 \%$ & - & - & \\
\hline \multirow{2}{*}{ Finland } & 2003 & - & - & 3 & - & - & - & \multirow{2}{*}{ [20] } \\
\hline & 2005 & 2 or 3 & $>99 \%$ & 2 or 3 & - & 3 & - & \\
\hline \multirow{2}{*}{ Netherlands } & 2001 & - & - & 3 or 5 & $>95 \%$ & - & - & \multirow{2}{*}{ [40] } \\
\hline & 2005 & 3 or 5 & $>95 \%$ & - & - & - & - & \\
\hline \multirow{2}{*}{ Norway } & 1998 & 3 & $>90 \%$ & - & - & - & - & \multirow{2}{*}{ [41] } \\
\hline & 2006 & - & - & 2 & $90 \%$ & - & - & \\
\hline \multirow{2}{*}{ Sweden } & 1996 & 1,2 or 3 & $298 \%$ & - & - & - & - & \multirow{2}{*}[40,42]{} \\
\hline & 2007 & - & - & 2 or 3 & $90 \%$ & - & - & \\
\hline \multirow{3}{*}{ United Kingdom ${ }^{\mathrm{b}, \mathrm{d}}$} & 2000 & 3 & $>90 \%$ & - & - & - & - & \multirow{3}{*}{ [43] } \\
\hline & Oct 2001 & - & - & 3 or 5 & - & - & - & \\
\hline & 2004 & 5 & - & 3 or 5 & - & - & - & \\
\hline
\end{tabular}

ACV: acellular pertussis vaccine; FHA: filamentous haemagglutinin; Fim2: serotype 2 fimbriae; Fim3: serotype 3 fimbriae; Prn: pertactin; Ptx: pertussis toxin.

Dashes are used where data are not applicable.

a The year in which ACVs were introduced as the primary series and as booster.

b In the United Kingdom, an $\mathrm{ACV}_{3}$ was used temporarily for the primary series until 2001. Thereafter, the whole cell pertussis vaccines was used again for the primary series, with addition of an ACV 3 or ACV 5 childhood booster in October 2001 . Subsequently, in 2004 the ACV 5 was introduced permanently for the primary series.

Vaccine compositions are shown. ACV1: Ptx monocomponent; ACV2: Ptx, FHA; ACV3: Ptx, FHA, Prn; ACV5: Ptx, FHA, Prn, Fim2, Fim3.

d For the purposes of this article, the United Kingdom is considered as one country.

do not produce FHA or Ptx. Hegerle et al. reported one isolate lacking both Prn and FHA, and one isolate lacking Ptx $[17,19]$. Bouchez et al. have suggested that the emergence of such isolates is related to the introduction of ACVs $[17,28]$. Prn-deficient isolates have been isolated from pertussis patients and seemed to be as virulent as isolates expressing Prn in infants less than six months of age as well as in a mouse model $[17,29]$. A better understanding of the epidemiology and virulence of Prn-deficient isolates is crucial for the development of next-generation pertussis vaccines.

In this study, we investigated the emergence and spread of Prn-deficient isolates in Europe. To do so, we combine single nucleotide polymorphism (SNP) typing, antigen expression analysis and DNA sequencing with epidemiological data. The diversity of vaccination programmes in Europe (Table 1) offers a unique opportunity to study the effect, if any, of vaccination policy on the emergence of Prn-deficient strains. Ultimately, we aim to define conditions that could prevent or hamper the emergence of vaccine-adapted strains. This study provides a baseline for future European studies in which the occurrence and spread of Prn-deficient strains will be investigated.

\section{Methods}

Analysis of Bordetella pertussis isolates

Six countries provided a total of 665 strains isolated from nasopharyngeal swabs from confirmed pertussis patients for this study: Denmark $(n=43)$, Finland $(n=56)$, Netherlands $(n=311)$, Norway $(n=20)$, Sweden $(n=197)$ and the UK (for the purposes of this article, the UK is considered as one country) $(n=38)$ (Table 2). These countries were selected as they are members of European research programme for improved pertussis strain characterisation and surveillance (EUPERTSTRAIN) network and were able to contribute strains. The strains were isolated during 1996 to 2012. In the countries studied, primary immunisation with ACVs was introduced between 1996 and 2005 (Table 1). Furthermore, in these countries, different ACVs and different vaccine strategies were used and the vaccine coverage varied (Table 1). Strains were grouped into three periods, 1996-2006, 2007-09 and 2010-12 (periods I, II and III, respectively). Bacteria were cultured on Bordet Gengou agar plates supplemented with $15 \%$ sheep blood and incubated at $35^{\circ} \mathrm{C}$ for 3 to 4 days.

PCR and DNA sequencing

DNA isolation was performed using the GenElute Bacterial Genomic DNA Kit (Sigma-Aldrich, Zwijndrecht, 


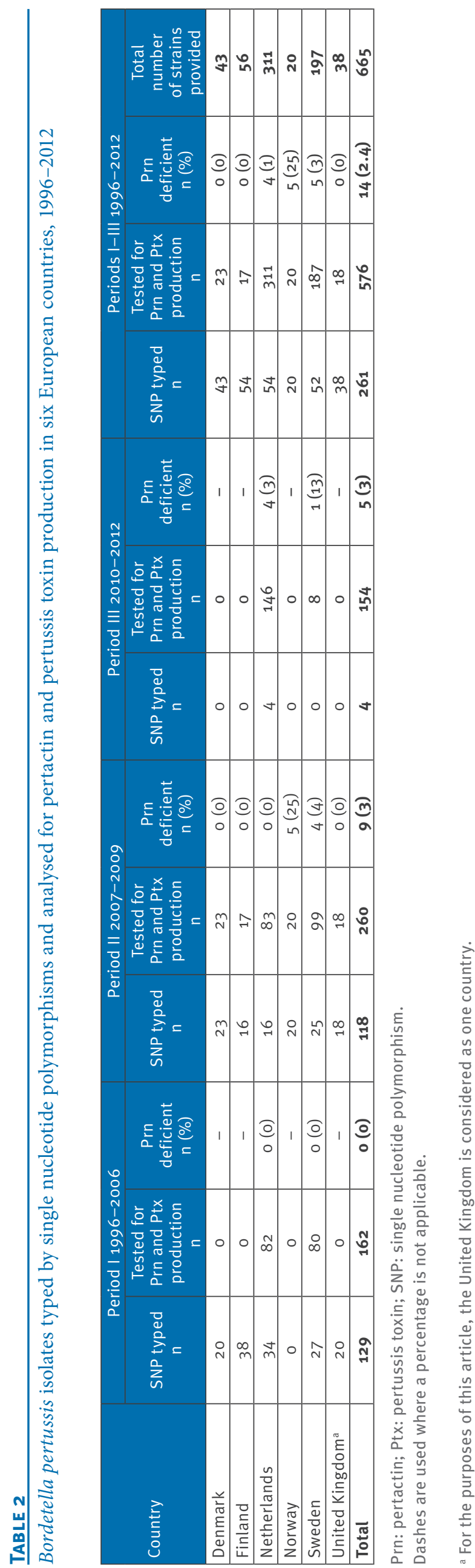

the Netherlands), following the manufacturer's instructions for Gram-negative bacteria. For multi-antigen sequence typing (MAST), the pertussis toxin promoter $(p t x P)$, regions 1 and 2 of the pertactin gene ( $p r n)$, the genes for serotype 2 fimbriae ( $f(m)$ ) and serotype 3 fimbriae ( $\left.f i_{3}\right)$ were sequenced in order to determine polymorphisms $[16,30]$.

To determine the location and size of the mutation causing non-expression of Prn, four sets of primers were selected for PCR amplification of the prn gene (Table 3). Prn PCR products were visualised and sized by capillary electrophoresis on a QIAxcel instrument (Qiagen Benelux), using the QIAxcel high-resolution kit, QX DNA size marker 250-8,000 base pairs (bp) and QX alignment markers $15 / 8,000 \mathrm{bp}$. Each type of mutation was verified in at least one isolate by Sanger sequencing using an $A B I 3700$ DNA sequencer (PerkinElmer Applied Biosystems).

\section{Identification of vaccine antigen-deficient isolates}

A microsphere-based Multiplex Immunoassay (Luminex, Austin, TX, US) [31] was developed to measure the expression of Ptx and Prn. Isogenic ptx (B0085) and prn (B1686) knockout strains were used as negative controls $[32,33]$. Analyses of these negative controls resulted in values $<5 \mathrm{ng} / \mathrm{ml}$. Therefore, isolates with antigen concentrations $<5 \mathrm{ng} / \mathrm{ml}$ were considered deficient isolates. All deficient isolates were tested at least twice, starting from independent cultures. In addition, Prn deficiency was verified with an immunoblot using the monoclonal antibody Prn Ab 62, E4D7 [34] (Figure 1).

Single nucleotide polymorphism typing and clustering analysis

SNP typing was used to establish genetic relationships between $B$. pertussis isolates [35,36]. A total of 113 SNPs that are useful for discriminating between isolates were selected after comparing whole genome data of a selection of 74 worldwide isolates (data not shown). In order to study the origin and spread of European Prndeficient isolates, SNP typing was performed on 261 isolates from all six countries using the Sequenom technology (Sequenom, San Diego, CA, US) [35]. At least 40 randomly selected strains (using the function RAND in Microsoft Excel) per country were typed, if available. A tree was constructed in Bionumerics $6 \cdot 6$ (Applied Maths, Sint-Martens-Latem, Belgium), treating the SNPs as character data and using the neighborjoining algorithm. The vaccine strains Booo6 (from the Netherlands, 1950, ptxP2), Bo499 (ACV strain 10-536, 1951, ptxP2) and Boo05 (from the Netherlands, 1950, $\left.p t x P_{1}\right)$ were included as outgroups. 


\section{TABLE 3}

Primers used for the characterisation of mutations leading to non-expression of pertactin in Bordetella pertussis isolates in six European countries, 1996-2012

\begin{tabular}{|c|c|c|c|c|}
\hline PCR & Primer name & Primer sequence ( $5^{\prime}$ to $\left.3^{\prime}\right)$ & Positiona & Reference \\
\hline \multirow{2}{*}{1} & prn-SPF1 & TCC CTG TTC CAT CGC GGT G & $1098036-1098054$ & \multirow{2}{*}{ [44] } \\
\hline & prn-SPR1 & CCT GAG CCT GGA GAC TGG & $1100878-1100895$ & \\
\hline \multirow{2}{*}{2} & prn-BF & AGC TGG GCG GTT CAA GGT & $1099489-1099506$ & \multirow{2}{*}{ [45] } \\
\hline & prn-BR & CGG AT T CAG GCG CAA CTC & $1100006-1100024$ & \\
\hline \multirow{2}{*}{3} & prn-D1F & CAT GAA ATC CGC CAT CCG CT & $1095775-1095794$ & \multirow{2}{*}{ [this work] } \\
\hline & prn-D1R & ACT GGC CCC CAA CAC AGA CA & $1098750-1098769$ & \\
\hline \multirow[b]{2}{*}{4} & prn-D2F & TAC TTT TGC TGC GCC CAT T & $1098015-1098033$ & \multirow{2}{*}{ [this work] } \\
\hline & prn-D2R & CTT GAT GGT GGT TCC GCT G & $1098283-1098301$ & \\
\hline
\end{tabular}

F: forward primer; R: reverse primer.

a Position of the primer, relative to the origin of replication of reference strain Tohama (National Center for Biotechnology Information (NCBI) reference sequence NC_002929).

\section{Results}

Frequency of pertactin-deficient isolates in six European countries

Expression of Prn was assessed by a multiplex Immunoassay assay and immunoblotting (Figure 1) for 576 of the 665 strains from the six countries, of which 14 (2.4\%) were shown to be Prn deficient (Tables 2 and 4). All 576 strains tested positive for Ptx production. For period I (1996-2006), only strains from the Netherlands $(n=82)$ and Sweden $(n=80)$ were available for this analysis. One Prn-deficient isolate from Finland was obtained in period I: this isolate was not included in the Prn-deficiency frequency analysis because no other Finnish isolates were analysed for Prn expression in that period. For period II (2007-09), between 17 and 99 strains from each of the six countries were analysed for Prn expression. Prn-deficient strains were observed in Norway (5/20 strains) and Sweden (4/99), but not in Denmark (o/23), Finland (o/17), the Netherlands (o/83) or the UK (o/18). As for period I, for period III (2010-12) only strains from the Netherlands $(n=146)$ and Sweden $(n=8)$ were available for this analysis. In that period, 4/146 Dutch strains and 1/8 Swedish strains were found to be Prn deficient. Thus, Prn-deficient isolates in the frequency analysis were detected in periods II and III. All isolates produced Ptx. The vaccination status of 14 of the 15 patients from whom the Prn-deficient isolates were recovered was unknown (Table 4). Therefore, we cannot relate the infection with a Prn-deficient strain to the degree of immunisation.

\section{Mutations causing non-expression of pertactin}

Previous studies observed five types of mutations that inactivate the prn gene: inversion, deletion of (part of) the gene, insertion of IS481 into prn, insertion of a single nucleotide resulting in a frameshift mutation, or a SNP resulting in the introduction of a stop codon [1722] (Figure 2, Table 5). We used PCR and sequencing of the prn gene to determine the cause of non-expression of the Prn-deficient isolates we analysed (Table 4). PCR fragment analysis showed that three Prn-deficient isolates (B3545, B3748, B3865) had an insertion of approximately 1 kilobase pair (kb) proximal to region
2 (Figure 3). We assumed this is the result of an insertion of IS 481 into this region and no further sequencing analysis was performed on these isolates. Sequence data of the remaining 12 Prn-deficient isolates showed that in two isolates, the promoter region was inverted as described by Pawloski et al. [22]. Another three isolates (B3582, B3640, B3891) had an IS element inserted proximal to one of the two repeat regions of the prn gene, designated region 2 (Figure 2). This mutation has also been found previously in French Prn-deficient isolates [17]. Sequence data of a sixth isolate (B3771), which originated from Finland in period I, contained a deletion of 49 bases in the signal sequence. This isolate was not included in the Prn-deficiency frequency analysis because no other Finnish isolates were analysed for Prn expression in period I. The seventh isolate, B3876 from The Netherlands, contained a SNP at position 223 that introduces a premature stop codon in the prnz gene. An eighth isolate (B3658), originating from Norway, also contained a SNP that introduces a premature stop codon in prn2, but at position 1,273. Sequencing of the prn gene around position 1,273 showed that the other four Norwegian Prn-deficient isolates also harboured this SNP.

\section{Phylogenetic relationships of European} pertactin-deficient Bordetella pertussis isolates Typing of 261 isolates from the six different European countries using 113 SNPs allowed us to distinguish 20 STs.

Phylogenetic analysis revealed a closely related European B. pertussis population (Figure 4). The tree topology showed two distinct clades containing $p t x P_{1}$ and ptxP $P_{3}$ isolates. In addition, a fim3.1 and a fimz.2 cluster could be observed within the $\operatorname{ptxP}_{3}$ clade (Figure 4).

The 12 European Prn-deficient isolates included in the phylogenetic analyses were found in four different STs: ST13, ST14, ST17 and ST19 (Figure 4). These STs were among the predominant types and contained $70 \%$ $(184 / 264)$ of the isolates analysed. 


\section{FIGURE 1}

Immunoblot to confirm absence of pertactin (69 kD) expression in Bordetella pertussis isolates in six European countries, 1996-2012

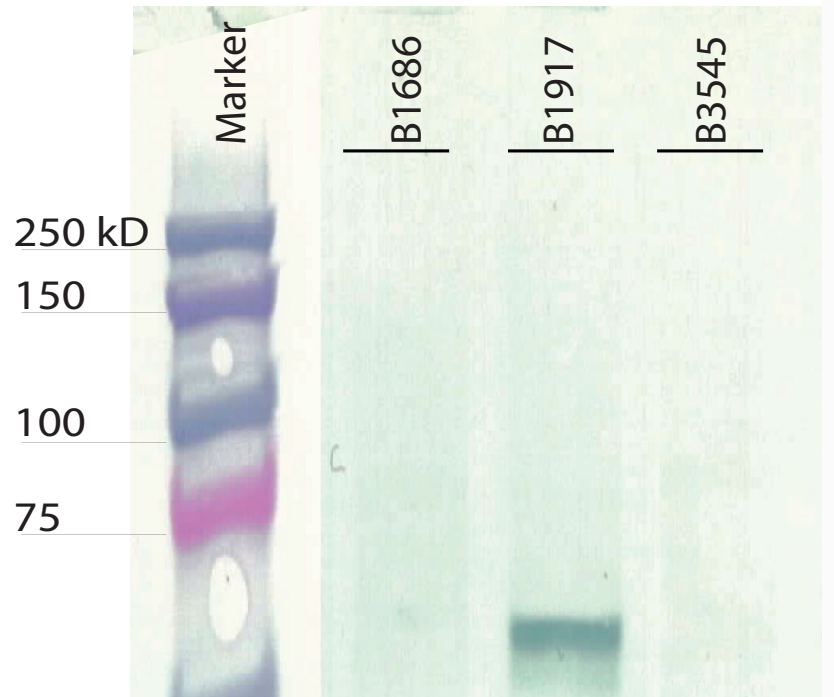

All Prn-deficient isolates analysed in this study were found in the $\operatorname{ptxP}_{3}$ clade but were associated with both fim3.1 and fim3.2 alleles. ST14 contains two types of prn mutations (Table 4). In contrast, the five Prndeficient isolates that belong to ST13 all harboured the same mutation in prn: a SNP resulting in premature translational termination of $p r n$. All five isolates were from Norway. The prn mutation, in which IS 481 was inserted proximal to region 2, was found in three STs that were dispersed across the $\mathrm{ptxP}_{3}$ clade. This mutation was associated with both the fim3.1 and fim3.2 alleles. Thus, identical mutations were observed in different STs, while within a single ST, different mutations were found.

\section{Discussion}

The diversity in immunisation programmes in Europe offers an opportunity to explore the effect of vaccination strategies on adaptation of $B$. pertussis in populations with a vaccine coverage between $80 \%$ and $96 \%$. In this study, the overall mean of Prn-deficient strains from six European countries isolated between 2007 and 2012 was $3.4 \%$ (14/414 isolates). Bouchez et al. suggested that the emergence of French Prn-deficient isolates was driven by the switch from WCVs to ACVs [17]. Indeed, Prn-deficient isolates were rarely found before the introduction of ACVs, when WCVs were used [37]. Compared with the mean of Prn-deficient strains found in the six countries studied here (3.4\%), higher percentages of Prn-deficient isolates were observed in France ( $13 \%$ in 2011), Japan (32\% in 2005-09) and the US $(53 \%$ in 2012) $[18,19,22]$. In Japan, ACVs were introduced in 1981 [18], and in the US, the first ACV was marketed in 1991. Thus, these countries have a longer history of ACV immunisation compared with the six countries included in this study, where ACVs vaccines for the primary series were introduced between 1996 and 2005 (Table 1). Interestingly, the early Prndeficient strains found in this study were mainly from Norway and Sweden, where ACVs for the primary series were introduced in 1996 and 1998, respectively, which is earlier than in the UK (in 2000), Finland and the Netherlands (both in 2005) (Table 1). Notably, in France an ACV booster was introduced in 1998, while the WCV for the primary series was replaced with an ACV in 2004 [29]. The timing of these changes is similar to that in Norway which, as in France, has a relatively high percentage of Prn-deficient strains. In Denmark, an ACV was introduced relatively early in 1997, while Prn-deficient strains were not detected. Unlike the vaccine in the other five countries in this study, which use ACVs containing Prn (Table 1), the Danish ACV contains Ptx only. As the Danish vaccine does not induce Prn antibodies, it is conceivable that Prn-deficient strains will not emerge in Denmark, if Prn-deficiency does not contribute to strain fitness, although overflow of Prn-deficient strains from neighbouring countries is possible.

In 2007-09, five of the 20 Norwegian strains were Prndeficient. Although the number of isolates tested was 
TABLE 4

Pertactin-deficient Bordetella pertussis isolates analysed from four European countries, 2004-12 (n=15)

\begin{tabular}{|c|c|c|c|c|c|c|}
\hline Isolate name & Patient's age & $\begin{array}{l}\text { Patient's } \\
\text { country of } \\
\text { residence }\end{array}$ & $\begin{array}{l}\text { Patient's } \\
\text { vaccination } \\
\text { status }\end{array}$ & $\begin{array}{l}\text { Year isolate } \\
\text { recovered }\end{array}$ & Sequence type $\mathrm{a}^{\mathrm{a}}$ & Mutation $^{b}$ \\
\hline B $3771^{\mathrm{c}}$ & 2 years & Finland & Vaccinated & 2004 & ST19 & $86: p r n 2\left(32 \_80 \Delta[49]\right)$ \\
\hline B3645 & 7 months & Norway & Unknown & 2007 & $\mathrm{ST} 13$ & 12: prn2 (1273STOP:C>T) \\
\hline B3652 & 14 years & Norway & Unknown & 2008 & $\mathrm{ST} 13$ & 口12: prn2 (1273STOP:C>T) \\
\hline B3654 & 14 years & Norway & Unknown & 2008 & $\mathrm{ST} 13$ & a12: prn2 (1273STOP:C>T) \\
\hline B3545 & Unknown & Sweden & Unknown & 2008 & ST17 & prn2 (PCRregion2::1kb) \\
\hline B3657 & 2 months & Norway & Unknown & 2009 & $\mathrm{ST} 13$ & a12: prn2 (1273STOP:C>T)) \\
\hline B3658 & 3 months & Norway & Unknown & 2009 & $\mathrm{ST} 13$ & 12: prn2 (1273STOP:C>T) \\
\hline B3594 & 1 month & Sweden & Unknown & 2009 & $\mathrm{ST} 14$ & a1: $\operatorname{prn} 2\left(-20892 \_-75<>[22 \mathrm{~kb}]\right)$ \\
\hline B3582 & o months & Sweden & Unknown & 2009 & $\mathrm{ST} 17$ & 4: prn2 (1613^1614::IS481[1049]) \\
\hline B3748 & 11 months & Sweden & Unknown & 2009 & ST17 & prn2 (PCRregion2::1kb) \\
\hline B3640 & 13 years & Netherlands & Unknown & 2010 & ST14 & 4: prn2 (1613^1614::IS481[1049]) \\
\hline B3865 & Unknown & Netherlands & Unknown & 2011 & $\mathrm{ST} 14$ & prn2 (PCRregion2::1kb) \\
\hline B3876 & 2 years & Netherlands & Unknown & 2011 & $\mathrm{NI}$ & 10: $p r n 2(223 S T O P: C>T)$ \\
\hline B3891 & Unknown & Sweden & Unknown & 2011 & $\mathrm{NI}$ & 4: prn2 (1613^1614::IS481[1049]) \\
\hline B3977 & 69 years & Netherlands & Unknown & 2012 & $\mathrm{NI}$ & 口1: prn2(-20892_-75<>[22kb]) \\
\hline
\end{tabular}

NI: not included in the SNP analysis; SNP: single nucleotide polymorphism; : mutation number.

a Sequence type as presented in Figure $2 \mathrm{~A}$.

${ }^{b}$ Mutation causing the non-expression of pertactin. Numbers correspond to those in Table 5 and Figure $2 \mathrm{~A}$.

' This isolate was not included in the frequency analysis, because it was a single analysed Finnish strain that was isolated before 2007 , but was included in SNP analysis and prn mutation analysis.

\section{FIGURE 2}

Mutations in prn2 causing non-expression of pertactin in Bordetella pertussis isolates in six European countries, 1996-2012

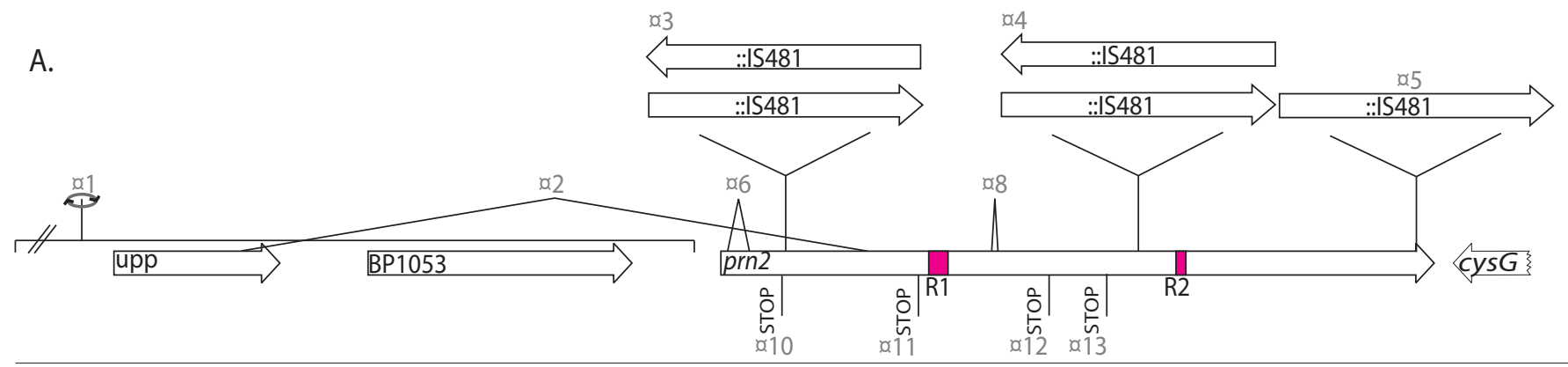

B.

prn2 MNMSLSRIVK AAPLRRTTLA MALGALGAAP AAHADWNNQS IVKTGERQHG

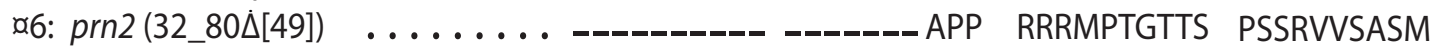

C.

1273

$\begin{array}{cccccccccc}\text { prn2 } & \text { GTA } & \text { AGC } & \text { GGC } & \text { CGT } & \text { CAG } & \text { GCC } & \text { CAG } & \text { GGC } & \text { ATC } \\ & \mathbf{V} & \mathbf{S} & \mathbf{G} & \mathbf{R} & \mathbf{Q} & \mathbf{A} & \mathbf{Q} & \mathbf{G} & \mathbf{I}\end{array}$

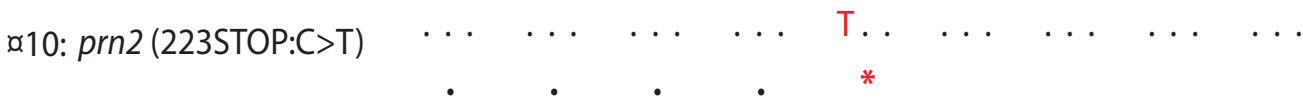

A. prn2 is shown with the surrounding genes. The arrowheads indicate the transcription direction. The variable regions 1 (R1) and 2 (R2) of prn are indicated in red. Numbers 1 to 13 refer to mutations ( $a$ ) in prn2 and correspond to the numbers in Table 5 .

B. Detailed representation of mutation $₫ 6$, a deletion of 49 bases in the signal sequence: prn2 (32 80-[49]): • identical bases/amino acids, deleted bases/amino acids.

C. Detailed representation of mutation $₫ 10$ : a SNP leading to a stop codon: prn2 (223STOP:C $>T$ ). Base and amino acid numbering is relative to the prnz initiation codon. 
TABLE 5

Mutations in the pertactin gene causing loss of pertactin expression

\begin{tabular}{|c|c|c|c|}
\hline $\begin{array}{l}\text { Number of the } \\
\text { mutation }^{\text {a }}\end{array}$ & Name of the mutation ${ }^{b}$ & Note & Reference \\
\hline$\not 1$ & prn2 (-20892_-75〈〉[22Kb]) & Inversion of about $22 \mathrm{~kb}$ in the promoter & {$[21$, this work] } \\
\hline$\$ 2$ & prn2 (-1846_5534[2399]) & Deletion of the first part of prn2 and upstream $B P 1053$ & [16] \\
\hline 93 & prn2 $\left(245^{\wedge} 246:: I S 481[1049]\right)$ & Insertion of IS481 in prn2, between position 245 and 246 & {$[20]$} \\
\hline$\$ 4$ & prn2 (1613^1614::IS481[1049]) & Insertion of IS481 in prn2, between position 1,613 and 1,614 & {$[16$, this work] } \\
\hline$\square 5$ & prn2 $\left(2735^{\wedge} 2736:: 1 S 481[1049]\right)$ & Insertion of IS 481 in prn2, between position 2,735 and 2,736 & {$[21]$} \\
\hline 86 & prn2 $\left(32 \_80 \Delta[49]\right)$ & Deletion in prn2 signal sequence & [this work] \\
\hline a7 & prn2 ( $\Delta \mathrm{prn})$ & Deletion of the entire prn gene & {$[18]$} \\
\hline 88 & prn2 (1043_1067ه[25]) & 25 bp deletion in first repeat region & [18] \\
\hline 99 & prn2 $(\Delta[89])$ & 89 bp deletion at 5 of prn & {$[18]$} \\
\hline 810 & prn2 (223STOP:C (T) & SNP C>T, leading to a stop codon & [this work] \\
\hline 211 & prn2 (760STOP:C $>T)$ & SNP C>T, leading to a stop codon & {$[21]$} \\
\hline Q12 & prn2 (1273STOP:C>T) & SNP C>T, leading to a stop codon & [20, this work] \\
\hline a13 & prn2 (1479STOP) & SNP leading to a stop codon & [18] \\
\hline 014 & prn1 (1598^1599::IS481[1049]) & Insertion of IS481 in prn1, also found in reverse direction & [17] \\
\hline 015 & prn1 $\Delta \mathrm{SS}$ & Deletion in prn1 signal sequence & {$[17,19,21]$} \\
\hline
\end{tabular}

bp: base pairs; IS: insertion element; kb: kilobase pairs; SNP: single nucleotide polymorphism; $a$ : mutation number.

a As presented in Figure 2, except for $₫ 14$ and 15 .

b The name is composed as follows: pertactin gene (prn) allele (position from open reading frame of the prn gene/type of mutation/[size of the mutation]).

$\begin{array}{ll}x_{-} y & \text { from position } x \text { to } y \\ x^{\wedge} y & \text { between position } x \text { and } y \\ \langle> & \text { inversion } \\ :: I S 481 & \text { insertion of IS } 481 \\ \Delta & \text { deletion } \\ \text { STOP:C }>T & \text { SNP }(C \text { to } T \text { ) leading to a premature stop codon }\end{array}$

low, this proportion is relatively high compared with the overall mean of the six countries in this period $3.4 \%$, 14/414). This implies that in Europe, besides France, Norway may also have elevated levels of Prn-deficient isolates. Comparisons of frequencies of Prn-deficient isolates should, however, be made with caution, as differences in the period investigated, vaccination policies and isolate collection are among the factors that can influence the outcome. It seems valid, though, to conclude that the fraction of Prn-deficient strains in several countries of Europe is relatively low, with the exception of France [19] and Norway, as stated above. In order to confirm these findings, further studies are required that include more isolates for each country. The analyses of larger amounts of Prn-deficient strains may also reveal if these strains are found in higher frequencies in particular age groups. Future studies should include more southern European countries.

Mutations that were previously found to inactivate the prn gene $[17,19,21]$ were also observed in the Prndeficient isolates analysed in this study. We found that the mutations in prn occurred several times independently in different lineages, which is an indication that it has been fixed in the population by positive selection. The European Prn-deficient isolates seem to have originated from distinct lineages, but within the diverse nature of the mutations causing non-expression, we also observed possible signs of clonal expansion of a Prn-deficient strain in Norway. Notably, the specific point mutation that occurred in five Norwegian isolates was also found in seven of 12 Prn-deficient isolates collected in Philadelphia in the US [21]. It was previously suggested that the spread of Prn-deficient isolates in Japan was the result of clonal expansion [18].

The production of bacterial virulence factors, such as pertactin, involves 'costs and benefits' for the bacteria. Costs include the energy used to express the virulence factors and activation of the host immune response against these antigens. Benefits comprise attachment to host tissues and manipulation of host defences. We hypothesise that the switch from WCV to ACV has affected the balance between these costs and benefits of Prn production to the extent that strains that do not produce Prn are able to expand. In support of this, our phylogenetic analysis indicates Prn-deficiency is subject to positive selection. We postulate that, because non-expression of one of the 


\section{FIGURE 3}

Characterisation of the prn gene from pertactin-deficient Bordetella pertussis isolates by polymerase chain reaction, from six European countries, 1996-2012

A.

$\$ 3$

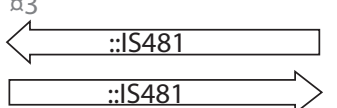

$\times 4$
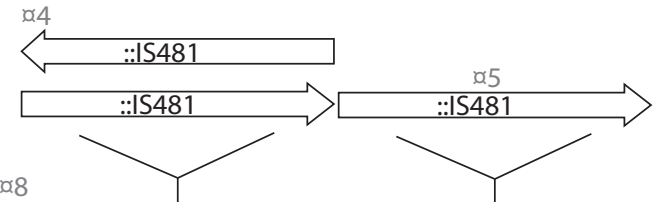

06
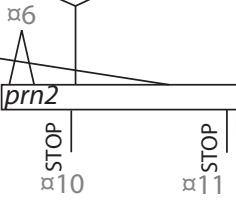

B.

PCR 1

PCR 2

PCR 3

\section{PCR 4}

C.

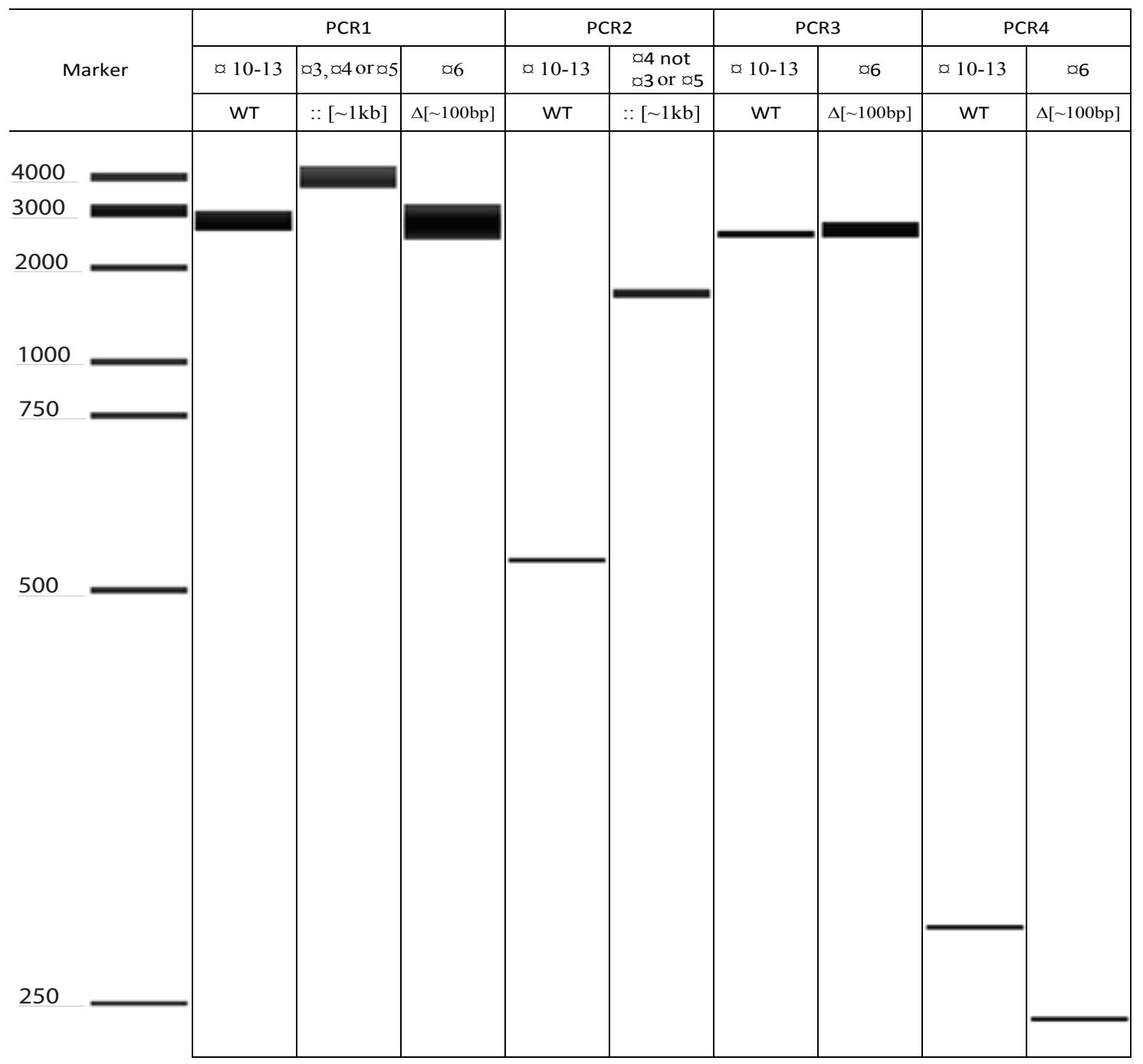

bp: base pairs; kb: kilobase pair; PCR: polymerase chain reaction; WT: wild type.

A. The prn gene and surrounding genes.

B. The grey bars represent the regions targeted in the PCR that were used to identify insertion and deletion mutations in prn. For the primers, see Table 3.

C. The PCR products of the WT prn allele were compared with PCR products derived from Prn-deficient strains. PCR fragments were sized by capillary electrophoresis. On the basis of the primers used and the size of the PCR fragments, the type of mutation was derived, as shown above the lanes. Designation of PCR fragments as in (B) and mutations as in Table 5. The first lane contains the size marker DNA (in bp). PCR2 distinguishes $\star_{4}$ from ${ }_{3}$ or ${ }_{5}$, which does not result from PCR1. Mutations 10-13 yielded WT products for the PCRs. 


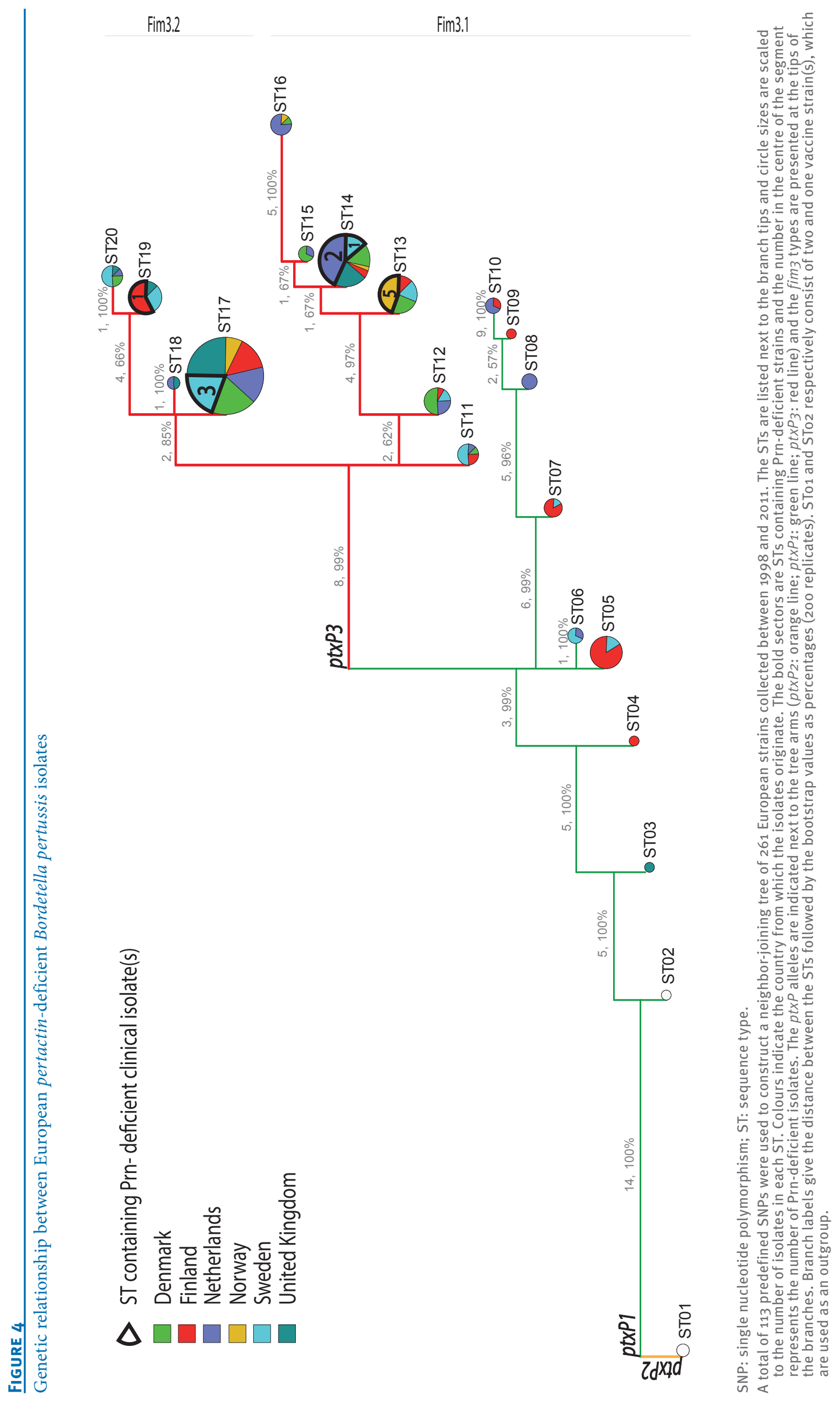


vaccine antigens contributes relatively little to immune evasion of a broad immune response, vaccination with WCVs limits the advantage of Prn-deficient isolates. Conversely, if the immune response is directed against a limited number of antigens (one to five in the case of $A C V s$ ), non-expression of one of the vaccine antigens may confer a considerable selective advantage. This is especially the case when high antibody titres are induced, as is observed for ACVs [38]. However, further studies are required to substantiate this hypothesis.

The emergence of Prn-deficient strains raises questions about its role in pertussis. An analysis of clinical symptoms caused by Prn-positive and Prn-negative isolates in infants did not reveal major differences between the two groups, which suggests that lack of Prn in $B$. pertussis does not affect virulence in infants substantially [29]. Other important questions that should be addressed in the future are the effect, if any, of Prn-deficiency on the efficacy of pertussis vaccines and whether Prn-deficient strains prevail more in groups with a particular level of immunity. This study establishes a baseline for investigations into the emergence and spread of Prn-deficient strains in Europe.

\section{Acknowledgements}

This project was supported by the National Institute of Public Health and the Environment (RIVM), The Netherlands (SOR project S/230456). All the authors are members of the European research programme for improved pertussis strain characterisation and surveillance (EUPERTSTRAIN) network.

\section{Conflict of interest}

None declared.

\section{Authors' contributions}

FRM obtained funding and supervised the study. QH and JM organised the EUPERTSTRAIN 2 and 3 collections from the network members. Isolates, epidemiological data and isolate characteristics were provided by all authors. AZ, MvG, KH, $\mathrm{HvdH}, \mathrm{MB}$ and FRM were responsible for the study concept and practical work. AZ and FRM analysed and interpreted data and wrote the manuscript. All authors were responsible for the critical revision of the manuscript.

\section{References}

1. Berbers GA, de Greef SC, Mooi FR. Improving pertussis vaccination. Hum Vaccin. 2009;5(7):497-503. http://dx.doi.org/10.4161/hv.8112

2. He Q, Mertsola J. Factors contributing to pertussis resurgence. Future Microbiol. 2008;3(3):329-39. http://dx.doi.org/10.2217/17460913.3.3.329

3. Mooi FR. Bordetella pertussis and vaccination: the persistence of a genetically monomorphic pathogen. Infect Genet Evol. 2010;10(1):36-49. http://dx.doi.org/10.1016/j.meegid.2009.10.007

4. Conyn van Spaendock MA, Van der Maas NA, Mooi FR. Control of whooping cough in the Netherlands: optimisation of the vaccination policy. Bilthoven: National Institute for Public Health and the Environment (RIVM); 2012. RIVM report 215121002. Synposis available from: http://www.rivm.nl/ en/Documents_and_publications/Scientific/Reports/2013/
februari/Control_of_whooping_cough_in_the_Netherlands_ Optimisation_of_the_vaccination_policy

5. Public Health England (PHE). Confirmed pertussis in England and Wales: data to end-December 2012. Health Protection Report. 2013;7(5). Available from: http://www.hpa.org.uk/hpr/ archives/2013/news0513.htm

6. Schmidtke AJ. Boney KO, Martin SW, Skoff TH, Tondella ML, Tatti KM. Population diversity among Bordetella pertussis isolates, United States, 1935-2009. Emerg Infect Dis. 2012;18(8):1248-55. http://dx.doi.org/10.3201/eid1808.120082

7. Mooi FR, Van Der Maas NA, De Melker HE. Pertussis resurgence: waning immunity and pathogen adaptation - two sides of the same coin. Epidemiol Infect. 2014;142(4):685-94. http://dx.doi.org/10.1017/So950268813000071

8. Ntezayabo B, De Serres G, Duval B. Pertussis resurgence in Canada largely caused by a cohort effect. Pediatr Infect Dis J. 2003;22(1):22-7. http://dx.doi.org/10.1097/00006454-200301000-00009

9. Tartof SY, Lewis M, Kenyon C, White K, Osborn A, Liko J, et al., Waning immunity to pertussis following 5 doses of DTaP. Pediatrics. 2013;131(4):e1047-52. http://dx.doi.org/10.1542/peds.2012-1928

10. Liko J, Robison SG, Cieslak PR. Priming with whole-cell versus acellular pertussis vaccine. N Engl J Med. 2013;368(6):581-2. http://dx.doi.org/10.1056/NEJMc1212006

11. Sheridan SL, Ware RS, Grimwood K, Lambert SB. Number and order of whole cell pertussis vaccines in infancy and disease protection. JAMA. 2012;308(5):454-6. http://dx.doi.org/10.1001/jama.2012.6364

12. Hallander HO, Andersson M, Gustafsson L, Ljungman M, Netterlid E. Seroprevalence of pertussis antitoxin (anti-PT) in Sweden before and 10 years after the introduction of a universal childhood pertussis vaccination program. APMIS. 2009;117(12):912-22. http://dx.doi.org/10.1111/j.1600-0463.2009.02554.x

13. Lam C, Octavia S, Bahrame Z, Sintchenko V, Gilbert GL, Lan R. Selection and emergence of pertussis toxin promoter $p t_{x} P_{3}$ allele in the evolution of Bordetella pertussis. Infect Genet Evol. 2012;12(2):492-5.

http://dx.doi.org/10.1016/j.meegid.2012.01.001

14. van Gent M, Bart MJ, van der Heide HG, Heuvelman KJ, Mooi FR. Small mutations in Bordetella pertussis are associated with selective sweeps. PLoS One. 2012;7(9): e46407. http://dx.doi.org/10.1371/journal.pone.0046407

15. Fry NK, Neal S, Harrison TG, Miller E, Matthews R, George RC. Genotypic variation in the Bordetella pertussis virulence factors pertactin and pertussis toxin in historical and recent clinical isolates in the United Kingdom. Infect Immun. 2001;69(9):5520-8.

http://dx.doi.org/10.1128/IAI.69.9.5520-5528.2001

16. Mooi FR, , van Loo IH, van Gent M, He Q, Bart MJ, Heuvelman $\mathrm{KJ}$, et al. Bordetella pertussis strains with increased toxin production associated with pertussis resurgence. Emerg Infect Dis. 2009;15(8):1206-13. http://dx.doi.org/10.3201/eid1508.081511

17. Bouchez V, Brun D, Cantinelli T, Dore G, Njamkepo E, Guiso $N$. First report and detailed characterization of B. pertussis isolates not expressing pertussis toxin or pertactin. Vaccine. 2009;27(43):6034-41

http://dx.doi.org/10.1016/j.vaccine.2009.07.074

18. Otsuka N, Han HJ, Toyoizumi-Ajisaka H, Nakamura Y, Arakawa $\mathrm{Y}$, Shibayama K, et al. Prevalence and genetic characterization of pertactin-deficient Bordetella pertussis in Japan. PLoS One. 2012;7(2): e31985. http://dx.doi.org/10.1371/journal.pone.0031985

19. Hegerle N, Paris AS, Brun D, Dore G, Njamkepo E, Guillot S, et al. Evolution of French Bordetella pertussis and Bordetella parapertussis isolates: increase of Bordetellae not expressing pertactin. Clin Microbiol Infect. 2012;18(9):E340-6. http://dx.doi.org/10.1111/j.1469-0691.2012.03925.x

20. Barkoff AM, Mertsola J, Guillot S, Guiso N, Berbers G, He Q. Appearance of Bordetella pertussis strains not expressing the vaccine antigen pertactin in Finland. Clin Vaccine Immunol. 2012;19(10):1703-4. http://dx.doi.org/10.1128/CVI.00367-12

21. Queenan AM, Cassiday PK, Evangelista A. Pertactin-negative variants of Bordetella pertussis in the United States. N Engl J Med. 2013;368(6):583-4.

http://dx.doi.org/10.1056/NEJMc1209369

22. Pawloski LC, Queenan AM, Cassiday PK, Lynch AS, Harrison MJ, Shang W, et al. Prevalence and molecular characterization of pertactin-deficient Bordetella pertussis in the United States. Clin Vaccine Immunol. 2014;21(2):119-25. http://dx.doi.org/10.1128/CVI.00717-13 
23. Advani A, Gustafsson L, Ahrén C, Mooi FR, Hallander HO. Appearance of Fim 3 and $p x_{x} P_{3}$-Bordetella pertussis strains, in two regions of Sweden with different vaccination programs. Vaccine. 2011;29(18):3438-42.

http://dx.doi.org/10.1016/j.vaccine.2011.02.070

24. Kallonen T, Mertsola J, Mooi FR, He Q. Rapid detection of the recently emerged Bordetella pertussis strains with the $p t x P_{3}$ pertussis toxin promoter allele by real-time PCR. Clin Microbiol Infect. 2012;18(10):E377-9.

http://dx.doi.org/10.1111/j.1469-0691.2012.04000.

25. Petersen RF, Dalby T, Dragsted DM, Mooi F, Lambertsen L. Temporal trends in Bordetella pertussis populations, Denmark, 1949-2010. Emerg Infect Dis. 2012;18(5):767-74. http://dx.doi.org/10.3201/eid1805.110812

26. Shuel M, Jamieson FB, Tang P, Brown S, Farrell D, Martin I, et al. Genetic analysis of Bordetella pertussis in Ontario, Canada reveals one predominant clone. Int J Infect Dis. 2013;17(6):e413 7. http://dx.doi.org/10.1016/j.ijid.2012.12.015

27. King AJ, van der Lee S, Mohangoo A, van Gent M, van der Ark A, van de Waterbeemd B. Genome-wide gene expression analysis of Bordetella pertussis isolates associated with a resurgence in pertussis: elucidation of factors involved in the increased fitness of epidemic strains. PLoS One. 2013;8(6):e66150. http://dx.doi.org/10.1371/journal.pone.0066150

28. Guiso N. Bordetella pertussis and pertussis vaccines. Clin Infect Dis. 2009;49(10):1565-9. http://dx.doi.org/10.1086/644733

29. Bodilis H, Guiso N. Virulence of pertactin-negative Bordetella pertussis isolates from infants, France. Emerg Infect Dis. 2013;19(3):471-4. http://dx.doi.org/10.3201/eid1903.121475

30. van Loo IH, Heuvelman KJ, King AJ, Mooi FR. Multilocus sequence typing of Bordetella pertussis based on surface protein genes. J Clin Microbiol. 2002;40(6):1994-2001. http://dx.doi.org/10.1128/JCM.40.6.1994-2001.2002

31. van Gageldonk PG, van Schaijk FG, van der Klis FR, Berbers $\mathrm{GA}$. Development and validation of a multiplex immunoassay for the simultaneous determination of serum antibodies to Bordetella pertussis, diphtheria and tetanus. J Immunol Methods. 2008;335(1-2):79-89. http://dx.doi.org/10.1016/j.jim.2008.02.018

32. van Gent M, van Loo IH, Heuvelman KJ, de Neeling AJ, Teunis $\mathrm{P}$, Mooi FR. Studies on Prn variation in the mouse model and comparison with epidemiological data. PLoS One. 2011;6(3):e18014. http://dx.doi.org/10.1371/journal.pone.0018014

33. Nicosia A, Perugini M, Franzini C, Casagli MC, Borri MG, Antoni $\mathrm{G}$, et al. Cloning and sequencing of the pertussis toxin genes: operon structure and gene duplication. Proc Natl Acad Sci U S A. $1986 ; 83(13): 4631-5$. http://dx.doi.org/10.1073/pnas.83.13.4631

34. Hijnen M, Mooi FR, van Gageldonk PG, Hoogerhout P, King AJ, Berbers GA. Epitope structure of the Bordetella pertussis protein P.69 pertactin, a major vaccine component and protective antigen. Infect Immun. 2004;72(7):3716-23. http://dx.doi.org/10.1128/IAl.72.7.3716-3723.2004

35. van Gent M, Bart MJ, van der Heide HG, Heuvelman KJ, Kallonen T, He Q, et al. SNP-based typing: a useful tool to study Bordetella pertussis populations. PLoS One. 2011;6(5):e20340. http://dx.doi.org/10.1371/journal.pone.0020340

36. Octavia S, Sintchenko V, Gilbert GL, Lawrence A, Keil $A D$, Hogg G, et al. Newly emerging clones of Bordetella pertussis carrying prnz and $p \mathrm{CP}_{3}$ alleles implicated in Australian pertussis epidemic in 2008-2010. J Infect Dis. 2012;205(8):1220-4. http://dx.doi.org/10.1093/infdis/jis178

37. Weber C, Boursaux-Eude C, Coralie G., Caro V., Guiso N. Polymorphism of Bordetella pertussis isolates circulating for the last 10 years in France, where a single effective whole-cell vaccine has been used for more than 30 years. J Clin Microbiol. 2001;39(12):4396-4403. http://dx.doi.org/10.1128/JCM.39.12.4396-4403.2001

38. Greco D, Salmaso S, Mastrantonio P, Giuliano M, Tozzi AE, Anemona A, et al. A controlled trial of two acellular vaccines and one whol cell vaccine against pertussis. N Engl J Med. 1996;334(6):341-8.

http://dx.doi.org/10.1056/NEJM199602083340601

39. Andersen PH, Knudsen LK, Valentiner-Branth P. DTAP-IPV/ HIB vaccination coverage 2011. Copenhagen: Statens Serum Institut; 2012. EPI-news. No 23a. Available from: http://www. ssi.dk/English/News/EPI-NEWS/2012/No\%2023a\%20-\%20 2012.aspx

40. van Amersfoorth SC, Schouls LM, van der Heide HG, Advani A, Hallander HO, Bondeson K, et al. Analysis of Bordetella pertussis populations in European countries with different vaccination policies. J Clin Microbiol. 2005;43(6):2837-43. http://dx.doi.org/10.1128/JCM.43.6.2837-2843.2005

41. Lavine JS, Bjørnstad ON, de Blasio BF, Storsaeter J. Shortlived immunity against pertussis, age-specific routes of transmission, and the utility of a teenage booster vaccine. Vaccine. 2012;30(3):544-51. http://dx.doi.org/10.1016/j.vaccine.2011.11.065

42. Advani A, Hallander HO, Dalby T, Krogfelt KA, Guiso N, Njamkepo E, et al. Pulsed-field gel electrophoresis analysis of Bordetella pertussis isolates circulating in Europe from 1998 to 2009. J Clin Microbiol. 2013;51(2):422-8. http://dx.doi.org/10.1128/JCM.02036-12

43. Campbell H, Amirthalingam G, Andrews N, Fry NK, George RC, Harrison TG, Miller E. Accelerating control of pertussis in England and Wales. Emerg Infect Dis. 2012;18(1):38-47. http://dx.doi.org/10.3201/eid1801.110784

44. Diavatopoulos DA, Cummings CA, Schouls LM, Brinig MM, Relman DA, Mooi FR. Bordetella pertussis, the causative agent of whooping cough, evolved from a distinct, human-associated lineage of B. bronchiseptica. PLoS Pathog. 2005;1(4):e 45. http://dx.doi.org/10.1371/journal.ppat.0010045

45. Mooi FR, van Oirschot $H$, Heuvelman K, van der Heide HG, Gaastra W, Willems RJ. Polymorphism in the Bordetella pertussis virulence factors P.69/pertactin and pertussis toxin in The Netherlands: temporal trends and evidence for vaccinedriven evolution. Infect Immun. 1998;66(2):670-5. 